Gut, 1960, 1, 326.

\title{
THE AUGMENTED HISTAMINE TEST WITH SPECIAL REFERENCE TO ACHLORHYDRIA
}

\author{
BY \\ SHEILA T. CALLENDER, F. P. RETIEF, and L. J. WITTS \\ From the Nuffield Department of Clinical Medicine, Radcliffe Infirmary, Oxford
}

\begin{abstract}
The Kay augmented histamine test has been used in a special study of 30 patients with pernicious anaemia and 136 other subjects suspected of having achlorhydria. The findings have been correlated with uropepsinogen excretion, serum levels of vitamin $\mathrm{B}_{12}$, and gastric biopsy. The definition of achlorhydria is specially considered.
\end{abstract}

For many years gastric secretion was estimated by techniques in which test meals were given by mouth and serial samples of gastric aspirate were titrated for acid. The neutralization of the gastric acid by the substance of the test meal and the practical difficulty of titrating a turbid fluid containing food residues led to the search for other methods of gastric stimulation. Solutions of caffeine and alcohol, even pure water, were experimented with but eventually they were replaced by the injection of histamine, which proved to be the ideal stimulant of the secretion of hydrochloric acid. The dosage of histamine was, however, limited by its systemic effects to a total of 0.5 to $1.0 \mathrm{mg}$. histamine acid phosphate, which may be an inadequate stimulus, particularly in patients disturbed by the procedure of intubation.

In 1953, Kay developed the augmented histamine test in which the dose of histamine was preceded by a dose of an antihistamine drug which blocks the systemic effects of the histamine but does not reduce the effect on gastric secretion. By means of dose response curves, Kay showed that a dose of $0.04 \mathrm{mg}$. per kilogram of body weight or more of histamine acid phosphate had a maximal stimulatory effect on the secretion of gastric acid. This was supported by Marks (1956) who correlated the findings in the augmented histamine test with the parietal cell mass in excised human stomachs. There are a few exceptions, e.g., antrectomy and vagotomy reduce the acid secretory response although the number of parietal cells remains unaffected (Kay, 1958), but in general the augmented histamine test may be regarded as providing a maximal stimulus to gastric secretion.

The objection of many people to intubation makes it difficult to establish the normal range of gastric secretion and the prevalence of achlorhydria. Published information is largely restricted to medical students and hospital patients. The largest series is that of Polland (1933). Using the single-dose histamine test, he found that the frequency of achlorhydria increased from zero below the age of 20 to approximately $30 \%$ at the age of 70 .

However, we now know that figures such as these represent the frequency of hypochlorhydria and achlorhydria combined, rather than achlorhydria alone. Using the augmented histamine test, Card, Marks, and Sircus (1955) found no instance of complete achlorhydria in the first 500 subjects they examined except in those with pernicious anaemia. Later, Card and Sircus (1958) showed that 29 out of 58 subjects who had been achlorhydric to $0.5 \mathrm{mg}$. histamine base secreted acid after $2.0 \mathrm{mg}$. histamine base; of the 29 who secreted no acid, 23 suffered from pernicious anaemia.

We report here our own experience with the augmented histamine test, with special reference to patients showing apparent achlorhydria but not suffering from pernicious anaemia. The test was applied to patients in whom achlorhydria had been diagnosed by means of the gruel test meal, a small dose of histamine, or the diagnex test (Denborough, Retief, and Witts, 1958). The loss of acid secretion has been correlated with other tests of gastric function, such as excretion of uropepsinogen and secretion of intrinsic factor, and with the gastric histology.

\section{MATERIAL}

The augmented histamine test was performed in 166 subjects.

Thirty had classical pernicious anaemia and were used as a standard of reference. Particular care was taken in 
this group to exclude any other possible cause for megaloblastic anaemia, e.g., steatorrhoea. The remaining 136 subjects were gathered from various sources.

Thirty-six were obtained through the records of the Department of Clinical Biochemistry. In these achlorhydria had been diagnosed as the result of a fractional test meal with gruel, or after $0.5 \mathrm{mg}$. of histamine subcutaneously, or with the two combined. Patients with pernicious anaemia were excluded from this group, as wcre subjects over 80 years of age or those suffering from gross disease.

In 71 patients achlorhydria had been diagnosed by the diagnex test; 32 of these suffered from irondeficiency anaemia; the remaining 39 were patients with miscellaneous conditions who had been admitted to a general medical ward.

Twelve subjects were relatives of patients with pernicious anaemia who had been found in a previous survey to have achlorhydria either to the diagnex test or the ordinary histamine test (Callender and Denborough, 1957).

Seventeen subjects had had no preliminary screening test.

Excluding the patients with pernicious anaemia, the augmented histamine test was performed in 136 subjects and achlorhydria or extreme hypochlorhydria was found in 64 . Eight of these 64 had had a partial gastrectomy and they will not be considered further here; 11 others were not studied further for various reasons. There thus remained 45 subjects who had achlorhydria or extreme hypochlorhydria in the augmented histamine test and who did not suffer from pernicious anaemia. The majority of these cooperated in further tests of gastric function.

\section{METHODS}

AUgmented Histamine Test.-The augmented histamine test was performed as originally described by Kay (1953) with minor modifications. Bronchial asthma was considered a contraindication. Pulse and blood pressure readings were recorded during the test and special care was taken when the systolic pressure fell below $110 \mathrm{~mm}$. Hg. A Ryle's tube was used for aspiration and was adjusted in position by radiographic screening until the tip lay over the vertebral column in the midline; then, with the patient lying on the left side, continuous aspiration was started by means of an electric pump. To ensure a steady flow, constant supervision was necessary and when the volumes of juice were small, as in pernicious anaemia, continuous suction by hand often proved essential. The patient was asked not to swallow saliva but to spit it out. After 15 minutes' aspiration an intramuscular injection of $100 \mathrm{mg}$. of mepyramine maleate ("anthisan") was given, followed half an hour later by a subcutaneous injection of $0.04 \mathrm{mg}$. per $\mathrm{kg}$. body weight of histamine acid phosphate. The 45-minute prehistamine sample was pooled but the posthistamine juice was collected as three separate quarter-hourly specimens.

Pre- and posthistamine samples were analysed as follows:-

(a) Volume was recorded in millilitres, and bile, mucus and blood content empirically indicated as ,,,- \pm+++ .

(b) The $p \mathrm{H}$ was determined in a direct-reading $p \mathrm{H}$ meter; occasionally samples were too small for this and "universal" indicator paper had to be used.

(c) Specimens were titrated with $\mathrm{N} / 20 \mathrm{NaOH}$ in a comparator block against a phosphate buffer standard of $p \mathrm{H} \mathrm{7.4;}$ neutral red was used as indicator.

The most direct measure of gastric secretion is the volume of juice produced on maximal stimulation. This is difficult to measure accurately as the stomach is open at both ends, but there is a close correlation between the volume of juice which can be aspirated and the amount of acid in it. Titration is not accurate when there is achlorhydria or hypochlorhydria, and it is essential to measure the $p \mathrm{H}$ of the gastric juice. Achlorhydria is theoretically present when the $p \mathrm{H}$ of the gastric juice is the same as that of the non-parietal gastric secretion, which is mainly derived from the pyloric glands, but this $p \mathrm{H}$ is not exactly known. Various arbitrary figures have been used such as 7.4, which is the $p \mathrm{H}$ of blood, 7.0, which is the physico-chemical neutrality, and 6.0 , which is the lowest level commonly found in pernicious anaemia.

It has long been a convention to define the presence or absence of acid secretion in terms of titration with Töpfer's reagent. Patients with gastric juice less acid than $p \mathrm{H} 3.5$ have been regarded as having achlorhydria. For the purpose of the present work we have extended this definition and applied the term "achlorhydria" when the $p \mathrm{H}$ of the gastric juice is never less than 3.5 and does not change more than one unit to the acid side after maximal stimulation with histamine. The term "hypochlorhydria" is used when the gastric juice becomes acid by more than one $p \mathrm{H}$ unit after histamine but does not become more acid than $p \mathrm{H} \mathrm{3.5.}$

UROPEPSINOGEN ESTIMATION.-The uropepsinogen was estimated on a 24-hour specimen of urine, collected under toluene, by the method of Anson (1938), as modified by Aitken, Spray, and Walters (1954). Aitken and her co-workers found a normal range of 60 to 250 units (mean 136 units) and for pernicious anaemia 0 to 55 units (mean 19 units). With the same method Retief (1959) found that 20 control subjects in the pernicious-anaemia age group excreted 8 to 266 units (mean 133.3 units) and 27 patients with pernicious anaemia 0 to 48 units (mean 19.4).

ESTIMATION OF INTRINSIC FACTOR.-Secretion of intrinsic factor was assessed indirectly by measuring the proportion of an oral dose of $0.5 \mu \mathrm{g}$. ${ }^{60} \mathrm{Co}$-labelled vitamin $B_{12}$ which was unabsorbed and excreted in the faeces. In patients with pernicious anaemia who lack intrinsic factor 60 to $100 \%$ of the radioactivity is recovered in the faeces, whereas in controls only 14 to $46 \%$ is found (Badenoch, Callender, Evans, Spray, Richards, Turnbull, Wakisaka, and Witts, 1955; Retief, 1959). Patients who showed defective absorption were asked to repeat the test. With the second test $50 \mathrm{mg}$. of an active preparation of intrinsic factor (Lederle, IFC 45774-133) was given by mouth with the radioactive vitamin $\mathbf{B}_{\mathbf{1 2}}$. 
Serum Vitamin $B_{12}$ Assay.-The level of serum vitamin $\mathbf{B}_{12}$ was assayed microbiologically; Lactobacillus leichmannii was used as test organism (Spray, 1955). With this method control values range between 150 and $1,000 \mu \mu \mathrm{g}$. per $\mathrm{ml}$.; in pernicious anaemia values are usually less than $100 \mu \mu \mathrm{g}$. per ml. (Spray and Witts, 1958).

GASTRIC Biopsy.-Wood's flexible biopsy tube was used to take biopsies of the gastric mucosa under radiological control (Wood, Doig, Motteram, Weiden, and Moore, 1949). Specimens were divided into three groups according to the histological appearances (Badenoch, Evans, and Richards, 1957):-

Group I: Normal mucosa or superficial gastritis with no significant atrophy of gastric glands.

Group II: Atrophic gastritis with mild to moderate glandular atrophy.

Group III: Severe glandular atrophy of the degree associated with pernicious anaemia. These were subdivided into severe atrophic gastritis where there was evidence of considerable inflammatory change and gastric atrophy with minimal inflammatory cell infiltration and complete absence of parietal cells.

\section{RESULTS}

General Observations on the Augmented Histamine Test.-The volume of saliva produced during the test is usually small and unlikely to contaminate gastric aspirate significantly, except in occasional instances, when it should be obvious.
The gastric tube was first passed until it was thought to be in the stomach. The patient was then screened and the tube manipulated if necessary. In $28 \%$ of patients the tip of the tube was initially placed unsatisfactorily, either at the cardia or lower oesophagus, or in the duodenum. In another $16 \%$ the tip was in the fundus and therefore not satisfactorily situated for maximal aspiration (Retief, 1959).

Anthisan caused obvious drowsiness in $61 \%$ of cases; this came on approximately 15 minutes after the injection and lasted up to two hours. Two to three minutes after the histamine injection $95 \%$ of subjects noticed a feeling of warmth which lasted about $\mathbf{3 0}$ minutes; the skin flushed visibly for $\mathbf{4 0}$ to 60 minutes, and in $12 \%$ a generalized blotchy erythema appeared which did not irritate. True urticaria was not seen. Other side-effects included headache $(7 \%)$, and lachrymation and nasal obstruction suggestive of hay fever $(6 \%)$. Bronchospasm was not noticed. Histamine caused a slight rise in blood pressure in $12 \%$ of cases, but a transient fall in blood pressure, lasting approximately 30 to 45 minutes, was more common $(61 \%)$. The drop in systolic pressure varied between $3 \mathrm{~mm}$. and $65 \mathrm{~mm}$. $\mathrm{Hg}$ (mean 19) and the diastolic between $3 \mathrm{~mm}$. and $40 \mathrm{~mm} . \mathrm{Hg}$ (mean 13). In one subject only was it considered wise to discontinue the test because of

TABLE I

THE AUGMENTED HISTAMINE TEST IN PERNICIOUS ANAEMIA SHOWING VOLUME AND $p$ H OF ASPIRATE

\begin{tabular}{|c|c|c|c|c|c|c|c|c|c|c|}
\hline \multirow{3}{*}{ Subject } & \multirow{2}{*}{\multicolumn{2}{|c|}{ Prehistamine Aspirate }} & \multicolumn{6}{|c|}{ Posthistamine Aspirate } & \multirow{3}{*}{$\begin{array}{l}\text { Total Vol. } \\
\text { (ml.) }\end{array}$} & \multirow{3}{*}{$\begin{array}{c}\text { Maximum } \\
\text { pH } \\
\text { Change }\end{array}$} \\
\hline & & & \multicolumn{2}{|c|}{ 15-Min. Specimen } & \multicolumn{2}{|c|}{ 30-Min. Specimen } & \multicolumn{2}{|c|}{ 45-Min. Specimen } & & \\
\hline & $\begin{array}{l}\text { Vol. } \\
\text { (ml.) }\end{array}$ & $\underset{\text { (units) }}{p H}$ & $\begin{array}{l}\text { Vol. } \\
\text { (ml.) }\end{array}$ & $\underset{\text { (units) }}{p \mathbf{H}}$ & $\begin{array}{l}\text { Vol. } \\
\text { (ml.) }\end{array}$ & $\underset{\text { (units) }}{p H}$ & $\begin{array}{l}\text { Vol. } \\
\text { (ml.) }\end{array}$ & $\underset{\text { (units) }}{p \mathbf{H}}$ & & \\
\hline $\begin{array}{l}\text { P.T. } \\
\text { A.H. } \\
\text { W.B. } \\
\text { C.L. } \\
\text { J.Ha. } \\
\text { L.McI. } \\
\text { B.V. } \\
\text { E.W. } \\
\text { L.P. } \\
\text { C.R. } \\
\text { R.W. } \\
\text { F.B. } \\
\text { M.G. } \\
\text { M.B. } \\
\text { H.F. } \\
\text { E.J. } \\
\text { J.H. } \\
\text { J.M. } \\
\text { W.D. } \\
\text { A.W. } \\
\text { S.W. } \\
\text { T.S. } \\
\text { E.A. } \\
\text { F.R. } \\
\text { D.J. } \\
\text { R.C. } \\
\text { M.S. } \\
\text { W.R. } \\
\text { W.Y. } \\
\text { D.E. }\end{array}$ & $\begin{array}{r}13.0 \\
11.9 \\
26.0 \\
18.6 \\
5.8 \\
21 \cdot 0 \\
3.6 \\
30.0 \\
15.6 \\
10.6 \\
19.0 \\
11.0 \\
21.0 \\
11.8 \\
28.0 \\
15.4 \\
8.0 \\
0.5 \\
5.6 \\
27.8 \\
14.2 \\
13.0 \\
8.0 \\
12.0 \\
43.0 \\
4.3 \\
2.6 \\
4.0 \\
26.0\end{array}$ & $\begin{array}{l}6 \cdot 71 \\
6 \cdot 72 \\
6 \cdot 99 \\
7 \cdot 63 \\
7 \cdot 08 \\
7 \cdot 29 \\
8 \cdot 06 \\
6 \cdot 87 \\
7 \cdot 25 \\
7 \cdot 51 \\
7 \cdot 10 \\
7 \cdot 10 \\
7 \cdot 33 \\
7 \cdot 40 \\
7 \cdot 46 \\
7 \cdot 00 \\
7 \cdot 50 \\
7 \cdot 50 \\
7 \cdot 68 \\
7 \cdot 89 \\
7 \cdot 80 \\
7 \cdot 59 \\
7 \cdot 65 \\
7 \cdot 81 \\
8 \cdot 02 \\
7 \cdot 50 \\
8 \cdot 00 \\
8 \cdot 00 \\
7 \cdot 50 \\
7 \cdot 36\end{array}$ & $\begin{array}{c}7.8 \\
6.3 \\
9.5 \\
0.5 \\
0.5 \\
1.0 \\
3.4 \\
6.8 \\
8.9 \\
2.8 \\
4.5 \\
2.8 \\
3.8 \\
2.0 \\
0.0 \\
6.6 \\
1.5 \\
0.5 \\
1.2 \\
2.8 \\
8.0 \\
5.5 \\
0.0 \\
8.0 \\
9.3 \\
0.7 \\
\text { Trace } \\
0.5 \\
7.0\end{array}$ & $\begin{array}{l}7 \cdot 72 \\
6 \cdot 84 \\
6 \cdot 80 \\
8 \cdot 00 \\
7 \cdot 50 \\
8 \cdot 00 \\
8 \cdot 86 \\
7 \cdot 52 \\
7 \cdot 56 \\
7 \cdot 91 \\
7 \cdot 46 \\
7 \cdot 15 \\
7 \cdot 94 \\
8 \cdot 00 \\
7 \cdot 49 \\
8 \cdot 00 \\
8 \cdot 00 \\
7 \cdot 00 \\
7 \cdot 82 \\
8 \cdot 13 \\
7 \cdot 54 \\
7 \cdot 85 \\
7 \cdot 9.98 \\
7 \cdot 50 \\
8 \cdot 00 \\
8 \cdot 00 \\
7 \cdot 50 \\
7 \cdot 18\end{array}$ & $\begin{array}{r}2.5 \\
3.6 \\
5.0 \\
7.8 \\
\text { Trace } \\
3.0 \\
2.3 \\
11.8 \\
5.7 \\
4.5 \\
2.5 \\
10.4 \\
7.2 \\
1.0 \\
0.0 \\
3.8 \\
0.0 \\
\text { Trace } \\
0.5 \\
4.4 \\
9.6 \\
9.5 \\
2.5 \\
0.0 \\
1.5 \\
10.0 \\
2.2 \\
\text { Trace } \\
0.6 \\
3.2\end{array}$ & $\begin{array}{l}8 \cdot 36 \\
8 \cdot 01 \\
8 \cdot 10 \\
8 \cdot 59 \\
8 \cdot 00 \\
8 \cdot 19 \\
8 \cdot 70 \\
7 \cdot 47 \\
7 \cdot 54 \\
8 \cdot 18 \\
7 \cdot 65 \\
7 \cdot 75 \\
8 \cdot 06 \\
8 \cdot 00 \\
7 \cdot 53 \\
8 \cdot 00 \\
8 \cdot 00 \\
8 \cdot 00 \\
7 \cdot 71 \\
7 \cdot 74 \\
7 \cdot 84 \\
7 \cdot 65 \\
8 \cdot 10 \\
7 \cdot 50 \\
8 \cdot 00 \\
8 \cdot 00 \\
7 \cdot 50 \\
7 \cdot 18\end{array}$ & $\begin{array}{r}3.6 \\
0.8 \\
5.0 \\
9.0 \\
\text { Trace } \\
8.0 \\
1.9 \\
7.6 \\
6.5 \\
5.8 \\
2.6 \\
4.2 \\
1.4 \\
12.8 \\
1.8 \\
1.0 \\
0.5 \\
2.0 \\
2.8 \\
4.6 \\
4.8 \\
\text { Trace } \\
2.0 \\
8.8 \\
9.3 \\
1.0 \\
0.6 \\
2.0 \\
1.8\end{array}$ & $\begin{array}{l}8 \cdot 12 \\
8.04 \\
7.23 \\
8.00 \\
7.70 \\
8.00 \\
7.58 \\
7.94 \\
8.02 \\
7 \cdot 76 \\
7.25 \\
8.00 \\
7.65 \\
8.06 \\
7 \cdot 53 \\
8.00 \\
8.00 \\
8.06 \\
8.26 \\
7.84 \\
7.71 \\
7.50 \\
8.00 \\
8.17 \\
7.50 \\
8.00 \\
8.00 \\
7.26 \\
7.03\end{array}$ & $\begin{array}{c}13.9 \\
10.7 \\
19.5 \\
17.3 \\
0.5 \\
12.0 \\
7.6 \\
26.2 \\
21.1 \\
13.1 \\
9.6 \\
17.4 \\
12.4 \\
15.8 \\
1.8 \\
11.4 \\
2.0 \\
2.5 \\
4.5 \\
11.8 \\
\quad 7 \\
22.4 \\
8.0 \\
2.0 \\
18.3 \\
28.8 \\
3.9 \\
0.6 \\
3.1 \\
12.0\end{array}$ & $\begin{array}{c}+1.65 \\
+1.29 \\
+1.11 \\
+0.96 \\
+0.92 \\
+0.90 \\
+0.80 \\
+0.71 \\
+0.69 \\
+0.67 \\
+0.66 \\
+0.65 \\
+0.63 \\
+0.60 \\
+0.60 \\
+0.53 \\
+0.50 \\
+0.50 \\
+0.38 \\
+0.35 \\
+0.33 \\
+0.25 \\
+0.20 \\
+0.19 \\
+0.15 \\
0 \\
0 \\
0 \\
-0.24 \\
-0.33\end{array}$ \\
\hline Mean & 14.9 & $7 \cdot 44$ & 3.9 & $7 \cdot 69$ & 3.6 & $7 \cdot 87$ & 3.9 & $7 \cdot 79$ & $11 \cdot 4$ & +0.52 \\
\hline
\end{tabular}


hypotension. The pulse rate increased in $70 \%$ of patients (mean 11 beats per minute; maximum 52 beats per minute); in $16 \%$ the rate slowed somewhat.

Augmented Histamine Test in Pernicious ANAEMIA.-The disease classically associated with achlorhydria is pernicious anaemia. An augmented histamine test was done on 30 patients with this disease to obtain a standard of reference. The gastric aspirate showed various degrees of bile staining in 27 of the 30 subjects, with no significant difference between pre- and posthistamine samples. There was obvious mucus in the juice from all but two patients and traces of blood were evident in seven. The volume of aspirate was invariably small (Table I).

In four patients only did the total volume of juice after histamine exceed $20 \mathrm{ml}$; three of these showed heavy bile staining suggestive of considerable duodenal regurgitation. There was no evidence of increased secretion after histamine stimulation. The mean total posthistamine volume $(11.4 \mathrm{ml}$.) was in fact less than the mean prehistamine aspiration over the same period of time (14.3 ml.).

Electrometric measurements revealed a prehistamine juice more alkaline than $p \mathrm{H} \mathrm{7.0} \mathrm{in} \mathrm{all} \mathrm{but}$ four instances and the lowest reading was $p \mathrm{H} \mathrm{6.71}$ (Table I). In two cases only did the $p \mathrm{H}$ change to the acid side after histamine and the shift was less than 0.33 units. In three there was no change in $p \mathrm{H}$; in all the others the $p \mathrm{H}$ rose after histamine (Fig. 1).
The mean maximum $p \mathrm{H}$ change indicated an increased alkalinity of 0.52 units.

ACHLORHYDRIA AND HYPOCHLORHYDRIA UNASSOCIATED WITH Pernicious ANaemia.-In 45 subjects not suffering from pernicious anaemia, none of the samples was more acid than $p \mathrm{H} 3 \cdot 5$. These subjects were, therefore, by our definition, hypochlorhydric or achlorhydric. In 14 of these subjects the diagnosis was simple iron-deficiency anaemia, in four steatorrhoea, six were close relatives of patients with pernicious anaemia, four had rheumatoid arthritis, and 17 suffered from miscellaneous diseases, including gastric carcinoma, myxoedema, aplastic anaemia, and nutritional megaloblastic anaemia.

Visible bile was present in the juice of 38 patients. There was a tendency for bile staining to become more pronounced after histamine. Obvious mucus was present in variable amounts in the aspirate of all but one patient. There were traces of blood in 21 instances.

The volume of gastric juice obtained varied widely (Table II). The mean total posthistamine aspirate $(19.5 \mathrm{ml}$.) was no larger than the prehistamine sample $(20.5 \mathrm{ml}$.) collected over a similar period of time. Both these volumes are larger than those found in pernicious anaemia, but are considerably less than in normochlorhydric subjects (vide infra). There was no indication of an increased flow of secretion in response to histamine.

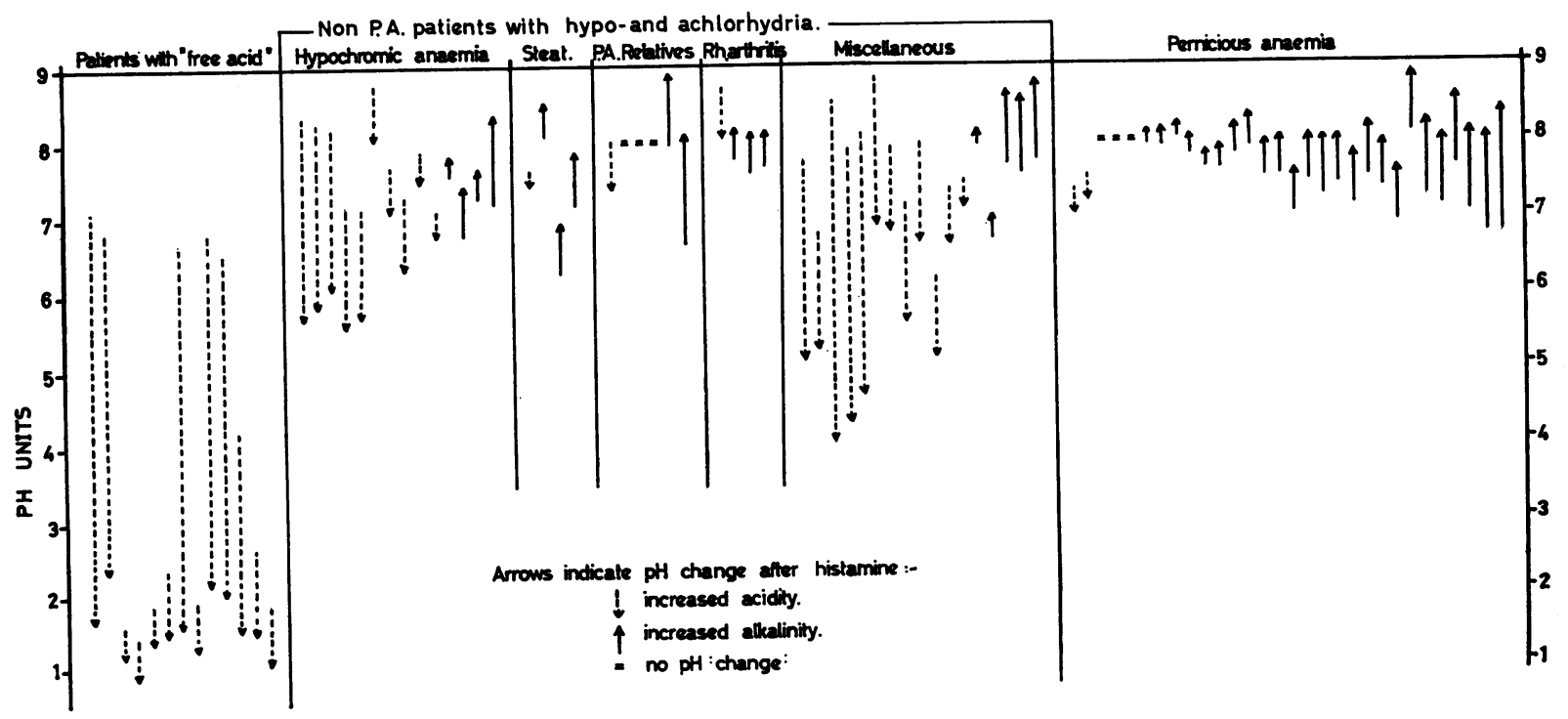

FIG. 1.-Maximum changes in the $\mathrm{pH}$ of gastric juice in response to the augmented histamine test in patients with (a) free acid, (b) hypo- and achlorhydria, and (c) pernicious anaemia. 
TABLE II

AUGMENTED HISTAMINE TEST IN ACHLORHYDRIA AND HYPOCHLORHYDRIA UNASSOCIATED WITH PERNICIOUS ANAEMIA

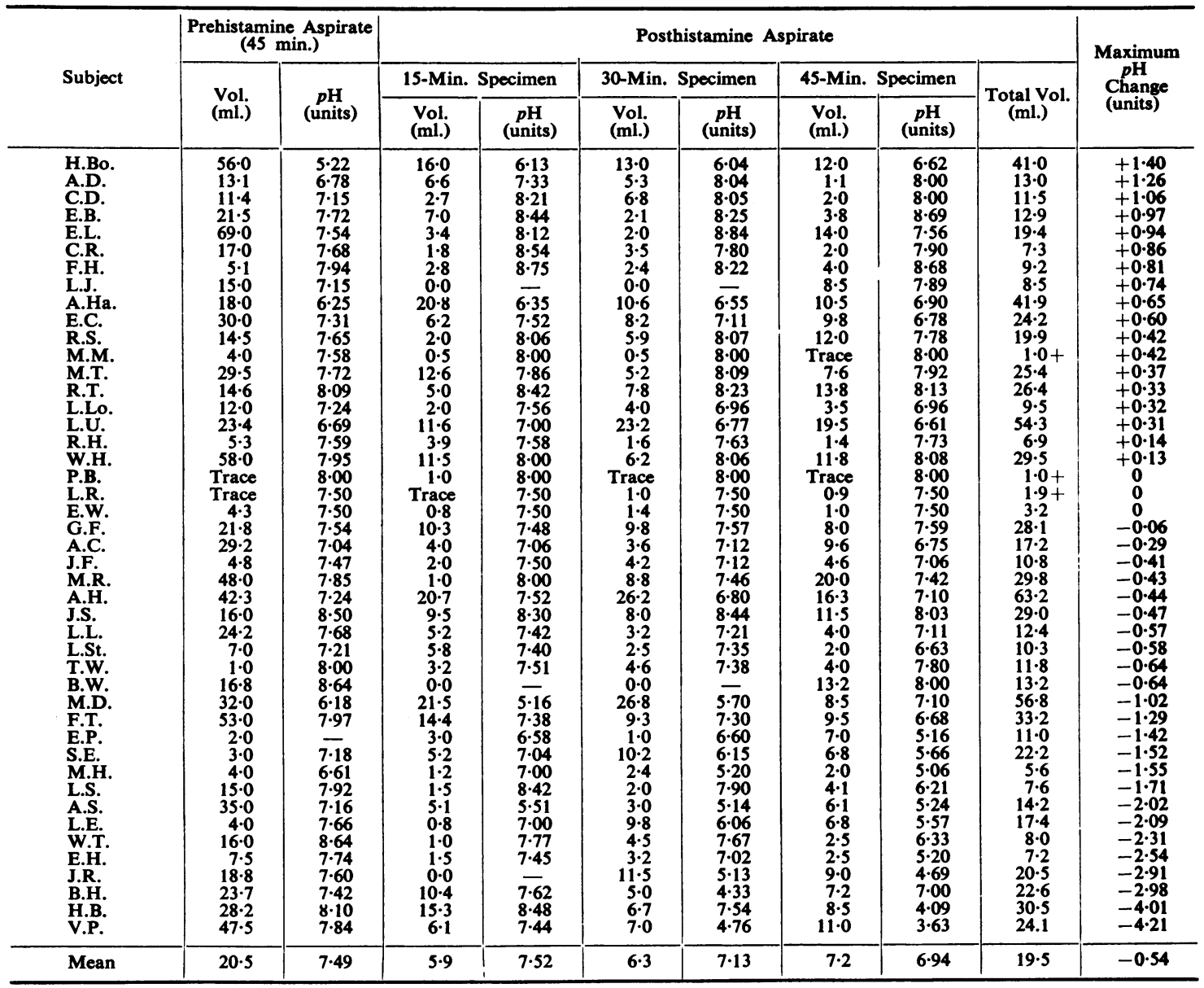

In 31 patients the $p \mathrm{H}$ showed a slight rise, no significant change, or fell by less than 1.0 unit after histamine. In these 31 , therefore, the test indicated achlorhydria indistinguishable from that found in pernicious anaemia. In the remaining 14 subjects the gastric juice showed a $p H$ fall of more than 1.0 with a maximum change of 4.21 units (Fig. 1); they showed, therefore, hypochlorhydria but not achlorhydria.

Titration of acid with $\mathrm{NaOH}$ was often technically difficult in view of the small volumes, the bile staining, and high mucus content of some specimens. There was no obvious correlation between $p \mathrm{H}$ values and titration figures (Fig. 2).

Persons with Adequate Acid Secretion.-The augmented histamine test was usually discontinued as soon as any sample more acid than $p \mathrm{H} 3.5$ was obtained, but it was completed in 13 consecutive subjects in whom acid had been found in the gastric juice. The results are discussed briefly here for comparison with the findings in achlorhydria and hypochlorhydria.

Obvious bile staining was evident in the juice from four patients and much mucus in two. Traces of blood were found in seven tests.

Individual volumes varied greatly but the mean total posthistamine aspirate of 45 minutes $(116 \mathrm{ml}$.) was much larger than the prehistamine collection (43 ml.; Table III). Both values greatly exceed those found in achlorhydria and hypochlorhydria. Quarter-hourly specimens showed maximal flow in the second and third posthistamine samples. Maximal acidity was invariably attained in the third 
TABLE III

AUGMENTED HISTAMINE TEST IN PATIENTS WITH FREE ACID

\begin{tabular}{|c|c|c|c|c|c|c|c|c|c|c|c|c|}
\hline \multirow{3}{*}{ Subject } & \multirow{3}{*}{$\begin{array}{c}\text { Age } \\
\text { (years) }\end{array}$} & \multirow{3}{*}{ Diagnosis } & \multicolumn{2}{|c|}{$\begin{array}{c}\text { Prehistamine } \\
\text { Aspiration }\end{array}$} & \multicolumn{8}{|c|}{ Posthistamine Aspiration } \\
\hline & & & \multirow{2}{*}{$\begin{array}{l}\text { Vol. } \\
\text { (mi.) }\end{array}$} & \multirow{2}{*}{$\underset{\text { (units) }}{p \mathbf{H}}$} & \multicolumn{2}{|c|}{ First Specimen } & \multicolumn{2}{|c|}{ Second Specimen } & \multicolumn{2}{|c|}{ Third Specimen } & \multirow{2}{*}{$\begin{array}{c}p H \\
\text { Change } \\
\text { (units) }\end{array}$} & \multirow{2}{*}{$\begin{array}{c}\text { Total } \\
\text { Volume } \\
\text { (ml.) }\end{array}$} \\
\hline & & & & & $\begin{array}{l}\text { Vol. } \\
\text { (ml.) }\end{array}$ & $\underset{\text { (units) }}{p \mathrm{H}}$ & $\begin{array}{l}\text { Vol. } \\
\text { (ml.) }\end{array}$ & $\begin{array}{c}p \mathrm{H} \\
\text { (units) }\end{array}$ & $\begin{array}{l}\text { Vol. } \\
\text { (ml.) }\end{array}$ & $\begin{array}{c}p \mathrm{H} \\
\text { (units) }\end{array}$ & & \\
\hline \multirow[t]{2}{*}{$\begin{array}{l}\text { K.B. } \\
\text { B.S. } \\
\text { H.P. } \\
\text { R.P. } \\
\text { L.P. } \\
\text { F.R. } \\
\text { R.B. } \\
\text { W.W. } \\
\text { M.A. } \\
\text { E.T. } \\
\text { M.S. } \\
\text { C.W. } \\
\text { A.P. }\end{array}$} & $\begin{array}{l}79 \\
70 \\
60 \\
60 \\
73 \\
26 \\
61 \\
64 \\
37 \\
39 \\
26 \\
61 \\
42\end{array}$ & $\begin{array}{l}\text { Hypochromic anaemia } \\
\text { Gastric ulcer } \\
\text { Hypochromic anaemia } \\
\text { Pyelonephritis } \\
\text { Hypochromic anaemia } \\
\text { Normal } \\
\text { Gastric ulcer } \\
\text { Gastric ulcer } \\
\text { Hypochromic anaemia } \\
\text { Duodenal and gastric ulcer } \\
\text { Normal } \\
\text { Duodenal ulcer } \\
\text { Duodenal ulcer }\end{array}$ & $\begin{array}{l}3.8 \\
4.6 \\
80.0 \\
28.0 \\
24.0 \\
33.0 \\
43.8 \\
43.0 \\
43.6 \\
13.8 \\
91.5 \\
56.5 \\
93.0\end{array}$ & $\begin{array}{l}6 \cdot 52 \\
6 \cdot 72 \\
6 \cdot 80 \\
7.07 \\
4 \cdot 25 \\
1.60 \\
6 \cdot 83 \\
2 \cdot 60 \\
2 \cdot 36 \\
1.90 \\
1.75 \\
1.42 \\
1.80\end{array}$ & $\begin{array}{r}3 \cdot 6 \\
2 \cdot 6 \\
7 \cdot .0 \\
33 \cdot 0 \\
4 \cdot 5 \\
14 \cdot 6 \\
26 \cdot 5 \\
21.0 \\
31 \cdot 0 \\
16 \cdot 0 \\
49 \cdot 0 \\
98 \cdot 0 \\
94 \cdot 0\end{array}$ & $\begin{array}{l}5.98 \\
3.40 \\
5.38 \\
5.54 \\
2.25 \\
1.46 \\
4.85 \\
1.75 \\
1.65 \\
1.45 \\
1.35 \\
1.15 \\
1.35\end{array}$ & $\begin{array}{r}13.6 \\
25.6 \\
25.5 \\
10.4 \\
28.0 \\
13.5 \\
32.0 \\
35.0 \\
33.0 \\
51.6 \\
65.0 \\
104.5 \\
150.5\end{array}$ & $\begin{array}{l}3 \cdot 25 \\
1 \cdot 85 \\
1.90 \\
1 \cdot 72 \\
1.85 \\
1.32 \\
2.61 \\
1.65 \\
1.46 \\
1.25 \\
1 \cdot 32 \\
1 \cdot 10 \\
1 \cdot 16\end{array}$ & $\begin{array}{r}4 \cdot 0 \\
23 \cdot 0 \\
14 \cdot 0 \\
13 \cdot 8 \\
30 \cdot 0 \\
44 \cdot 0 \\
18 \cdot 0 \\
27 \cdot 5 \\
34 \cdot 0 \\
56 \cdot 3 \\
71 \cdot 0 \\
78 \cdot 5 \\
95 \cdot 0\end{array}$ & $\begin{array}{l}2 \cdot 10 \\
1.60 \\
2 \cdot 38 \\
1 \cdot 66 \\
1.50 \\
1.28 \\
2 \cdot 31 \\
1.45 \\
1.40 \\
1 \cdot 10 \\
1.22 \\
0.96 \\
1 \cdot 16\end{array}$ & $\begin{array}{l}-4.42 \\
-5.12 \\
-4.42 \\
-5.41 \\
-2.75 \\
-0.32 \\
-4.51 \\
-1.15 \\
-0.94 \\
-0.80 \\
-0.53 \\
-0.46 \\
-0.64\end{array}$ & $\begin{array}{r}21 \cdot 2 \\
51 \cdot 2 \\
56 \cdot 5 \\
57.2 \\
62.5 \\
72.1 \\
76.5 \\
83 \cdot 5 \\
98 \cdot 0 \\
123.9 \\
185.0 \\
281.0 \\
339.5\end{array}$ \\
\hline & Mean & & $43 \cdot 0$ & 3.97 & $30 \cdot 8$ & $2 \cdot 89$ & $45 \cdot 2$ & $1 \cdot 73$ & $39 \cdot 2$ & 1.55 & -2.42 & $116 \cdot 0$ \\
\hline
\end{tabular}

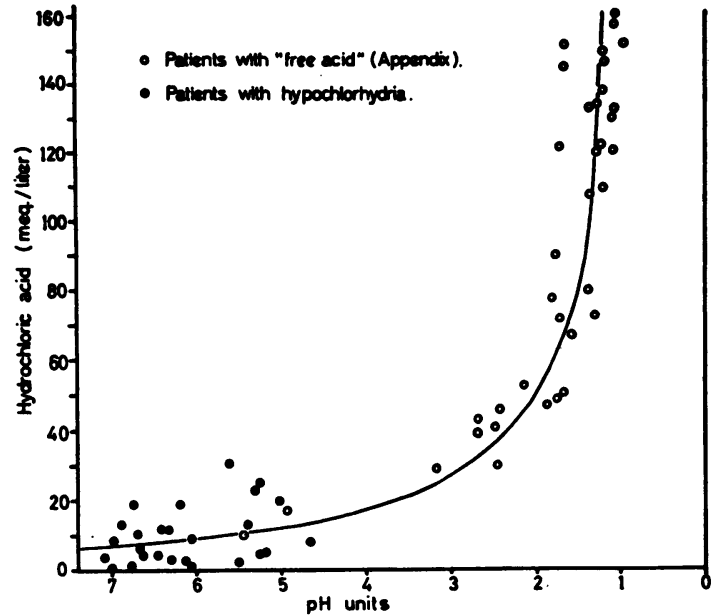

Fig. 2.-The comparison of $\mathrm{pH}$ values for gastric juice and results of titration with $\mathrm{N} / 20 \mathrm{NaOH}$ to $\mathrm{pH} 7 \cdot 4$.

quarter-hour after histamine, where the mean $p \mathrm{H}$ was 1.55 (Table III).

In these patients with free acid there was a relation between acid titration values and $p \mathrm{H}$ (Fig. 2).

Correlation between Gastric Acidity and EXCRETION OF UROPEPSINOGEN, ABSORPTION OF Vitamin $B_{12}$, Serum Vitamin $B_{12}$, AND Gastric Histology.-Whenever possible the 45 subjects with achlorhydria and hypochlorhydria unassociated with pernicious anaemia were investigated further and the acid secretion was compared with other indices of gastric mucosal function. In Figs. 3 to 5 these patients are divided into three groups according to whether there was a $p \mathrm{H}$ fall greater than one unit (group 1); a fall in $p \mathrm{H}$ of less than one unit (group 2); or no change in $p \mathrm{H}$ after histamine (group 3). Control values and values for pernicious anaemia are included in each figure.

Uropepsinogen Excretion.-Forty-three of the subjects collected a 24-hour specimen of urine for uropepsinogen estimation (Fig. 3). In 31 the results were within the range for pernicious anaemia, low values being found in hypochlorhydria as well as in achlorhydria. The mean values in the achlorhydric subjects came into the range for pernicious anaemia and were lowest in those showing no change in $p \mathrm{H}$. However, even in this group some values in the normal range were found.

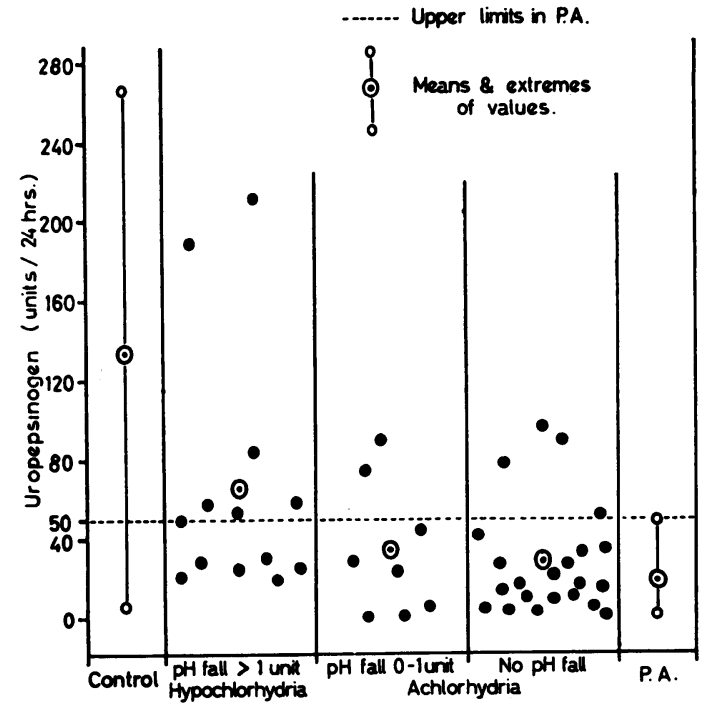

FIG. 3.-Values for uropepsinogen excretion in patients with hypochlorhydria and achlorhydria compared with those in control subjects and patients with pernicious anaemia. 


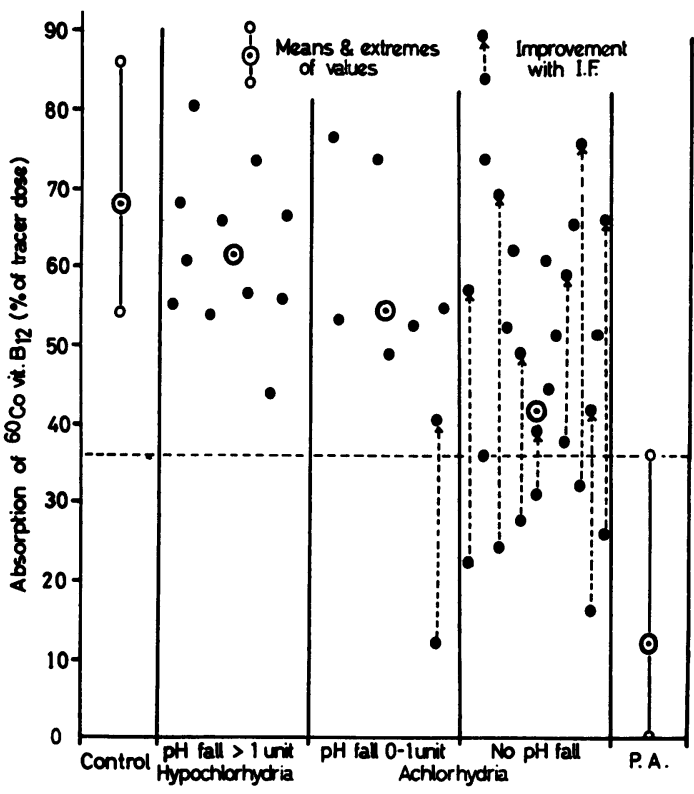

Fig. 4.-Absorption from $0.5 \mu \mathrm{g}$. dose of ${ }^{60}$ Co-labelled vitamin $B_{12}$ in patients with achlorhydria and hypochlorhydria compared with control subjects and patients with pernicious anaemia.

Absorption of ${ }^{60} \mathrm{Co}$-vitamin $\mathrm{B}_{12}$.-Thirty-five subjects agreed to have a test of absorption of labelled vitamin $B_{12}$ (Fig. 4). In our laboratory, patients with pernicious anaemia have been found to absorb 0 to $36.3 \%$ of an $0.5-\mu \mathrm{g}$. oral dose of ${ }^{60} \mathrm{Co}$-vitamin $\mathrm{B}_{12}$ with a mean of $12 \%$. The lowest absorption in a series of control subjects was $54 \%$. Nine of the present subjects showed a reduced absorption, in the range for pernicious anaemia, although only in one was absorption reduced as low as the mean for pernicious anaemia. None of these patients was anaemic. They all fell into the truly achlorhydric group and only one showed any fall in $p \mathrm{H}$ after histamine. When the test was repeated with intrinsic factor absorption was enhanced.

A further 10 subjects showed absorption of vitamin $B_{12}$ intermediate between the range for normal people and pernicious anaemia. Eight of these were achlorhydric and two hypochlorhydric. In the remaining 16 absorption of vitamin $B_{12}$ was normal.

It would appear from these results that although several of the patients show evidence of lack of intrinsic factor, inasmuch as they fail to absorb labelled vitamin $B_{12}$ normally, the defect is in general not as severe as in pernicious anaemia. This, together with the fact that some of those with complete achlorhydria show normal absorption, supports the view that intrinsic factor is lost from the gastric secretion at a later date than acid secretion in the process of progressive mucosal atrophy (Witts, 1932; Poliner and Spiro, 1958).

Serum Vitamin $B_{12}$ (Fig. 5).- Six patients were receiving vitamin $B_{12}$ therapy at the time of study.

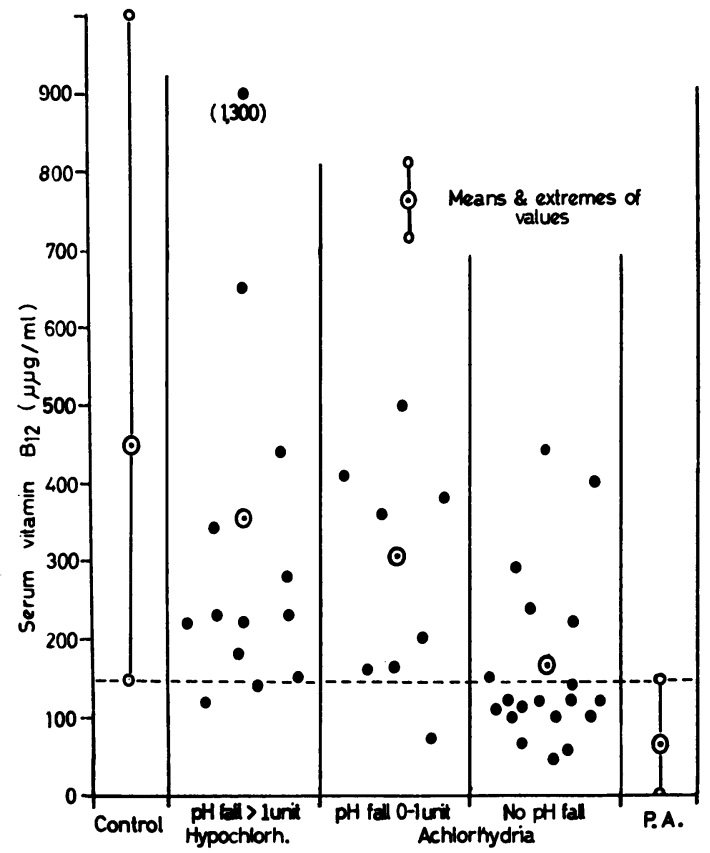

FIG. 5.-Levels of serum vitamin $B_{12}$ in patients with achlorhydria and hypochlorhydria compared with values for control subjects and patients with untreated pernicious anaemia.

TABLE IV

CORRELATION OF DIFFERENT ASPECTS OF GASTRIC FUNCTION IN HYPOCHLORHYDRIA AND ACHLORHYDRIA*

\begin{tabular}{|c|c|c|c|c|c|}
\hline & $\underset{\%}{\text { Hypochlorhydria }}$ & $\underset{\%}{\text { Achlorhydria }}$ & Low Uropepsin & $\begin{array}{c}\text { Low Absorption of } \\
\text { Vitamin } \mathbf{B}_{12}\end{array}$ & $\underset{\%}{\underset{\%}{\text { Low Serum }}}$ \\
\hline $\begin{array}{l}\text { Hypochlorhydria } \\
\text { Achlorhydria } \\
\text { Low uropepsin } \\
\text { Low absorption of vitamin } \mathbf{B}_{12} \\
\text { Low serum vitamin } \mathbf{B}_{\mathbf{1 2}}\end{array}$ & $\begin{array}{r}100 \\
0 \\
23 \\
0 \\
12\end{array}$ & $\begin{array}{r}0 \\
100 \\
77 \\
100 \\
88\end{array}$ & $\begin{array}{r}54 \\
80 \\
100 \\
100 \\
75\end{array}$ & $\begin{array}{r}0 \\
38 \\
38 \\
100 \\
53\end{array}$ & $\begin{array}{r}18 \\
54 \\
41 \\
89 \\
100\end{array}$ \\
\hline
\end{tabular}

${ }^{*}$ Low uropepsin $<50 \mathrm{u} . / 24 \mathrm{hrs}$. Low absorption of ${ }^{\circ 0} \mathrm{Co}-\mathrm{B}_{12}<40 \%$ tracer dose absorbed. Low serum vitamin $\mathrm{B}_{13}<150 \mu \mu \mathrm{g} . / \mathrm{ml}$. 
The remaining 39 showed values for the serum vitamin $B_{12}$ ranging from $45 \mu \mu \mathrm{g}$. per $\mathrm{ml}$. to $1,300 \mu \mu \mathrm{g}$. per ml., with a mean of $265 \mu \mu \mathrm{g}$. per ml. The lowest values were found in patients with achlorhydria and no fall in $p \mathrm{H}$ after histamine. In 13 out of 19 in this group the serum $B_{12}$ was in the range for pernicious anaemia, though the mean was just above this. In three patients who had shown a significant increase in the acidity of the gastric juice after histamine, the serum vitamin $B_{12}$ level was also in the range for pernicious anaemia. There was, however, evidence of prolonged malnutrition in these three subjects and the low serum levels may have been due to dietary deficiency of vitamin $B_{12}$ rather than defective absorption.

Histology of the Gastric Mucosa (Fig. 6).Suction biopsies were obtained in 28 of the 45 patients with achlorhydria or hypochlorhydria not suffering from pernicious anaemia. One further patient underwent a gastrectomy for carcinoma and the operation specimen was sectioned.

In order to correlate histology with function the three grades of mucosal degeneration have been compared with acidity changes, uropepsinogen excretion, vitamin $\mathbf{B}_{12}$ absorption, and serum vitamin $\mathbf{B}_{12}$ levels.

In this small series there was no linear relation between the degrees of atrophy on the one hand, and shift of $p \mathrm{H}$ after histamine, uropepsinogen values, or levels of serum vitamin $B_{12}$ on the other. However, there appeared to be a relation between loss of intrinsic factor and histology in that eight of the nine subjects who showed defective absorption of vitamin $B_{12}$ had advanced glandular atrophy. In the ninth there was moderate atrophy only. This relation was also evident in the serum levels of vitamin $B_{12}$ since 10 of the 12 who showed low levels of vitamin $B_{12}$ had severe gastric atrophy. The remaining two showed moderate atrophy only; one of these suffered from steatorrhoea.

Although gastric atrophy may represent the endstage of atrophic gastritis, there is no close correspondence between the different degrees of loss of secretory ability and the different stages of gastritis as diagnosed by biopsy. The hypochlorhydric patient with the greatest increase in acidity had gastric atrophy on histological examination.
FIG. 6.-Histology of the gastric mucosa compared with (a) acid secretion, (b) uropepsinogen excretion, (c) vitamin $B_{12} a b$ sorption, and (d) serum vitamin $B_{12}$. 1, No glandular atrophy; 2, moderate glandular atrophy; 3, severe glandular atrophy; $\boldsymbol{G A}$, gastric atrophy. (a) ACID SECRECTION

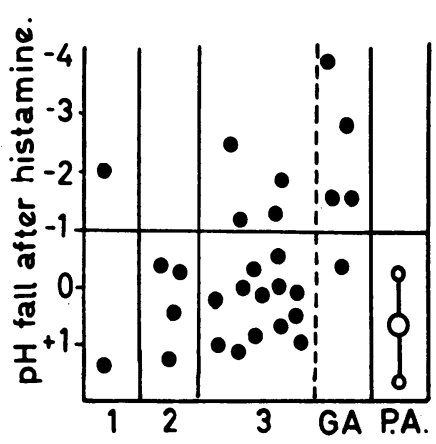

(c) VIT. $B_{12}$ ABSORPTION

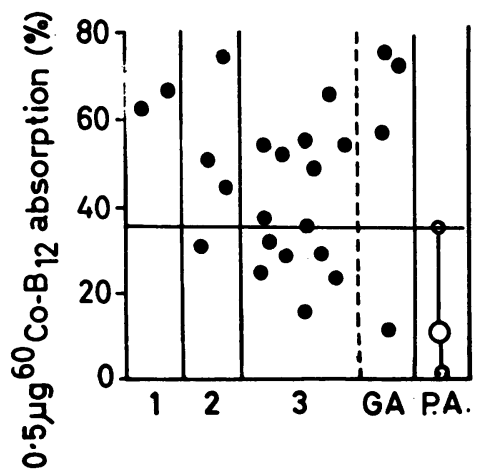

(b) UROPEPSINOGEN

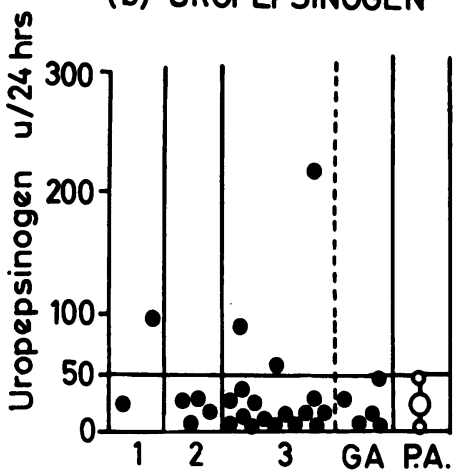

(d) SERUM VIT. $B_{12}$

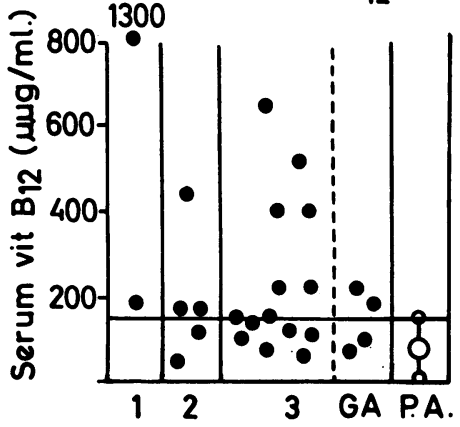




\section{Discussion}

An augmented histamine test is something of an ordeal for a patient. The patient must fast, a tube must be passed, its position in the stomach must be checked by radiological examination, histamine and antihistaminic must be given in high dosage, and a skilled operator must supervise the whole procedure. Experience with the test has nevertheless shown that the diagnosis of achlorhydria by other methods is frequently erroneous. In any form of direct gastric analysis the position of the tube is of major importance and errors can easily be made. In indirect analysis, as in the diagnex test, the sources of error are more numerous but inadequate stimulation of the gastric mucosa may be the most important. It is probable that most of the surveys made to date exaggerate the prevalence of achlorhydria. Excluding patients with pernicious anaemia, about $60 \%$ of our patients diagnosed as having achlorhydria by simpler tests showed normal acid secretion in the augmented histamine test.

Electrcmetric titration of the $p \mathrm{H}$ of the gastric juice after maximal stimulation with histamine appears to be the most sensitive way of distinguishing between achlorhydria and hypochlorhydria. On the strength of our findings in pernicious anaemia we suggest that a fall in $p \mathrm{H}$ greater than one unit probably indicates secretion of acid by the gastric mucosa. Although we started by using the conventional $p \mathrm{H} 3.5$ to separate those with normal acid secretion from those with hypo- and achlorhydria, our results indicate, like those of Card and Sircus (1958), that true achlorhydria is almost invariably associated with a $p \mathrm{H}$ greater than 6 . The terms "free acid" and "total acid" based on titration with Topfer's and other indicators are meaningless and are best avoided. Simple tests in vitro, in which known quantities of $\mathrm{HCl}$ are adced to alkaline gastric juice, show that the secretion of small amounts of acid will not be obvious unless careful measurements of $\mathrm{pH}$ are made (Retief, 1959).

$p \mathrm{H}$ readings are, however, of little value in assessing the quantity of acid secreted. Gastric juice is not a pure inorganic solution of acid but contains buffers which will influence direct calculations from the $p H$ (Retief, 1959). Titration with $\mathrm{NaOH}$ to a specific neutral $p \mathrm{H}$ is then indicated. Unfortunately no satisfactory end-point exists as the acidity of non-parietal gastric secretion is not known. We have used $p \mathrm{H} 7 \cdot 4$ (the approximate $p H$

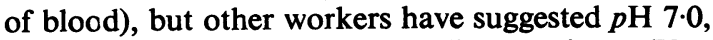
the physico-chemical neutrality point (Van Goidsenhoven, Wilkoff, and Kirsner, 1958) and 8.2 , the $p \mathrm{H}$ of canine mucus (Shay, Komarov, Siplet, and Fels, 1946). We found a satisfactory correlation between $p \mathrm{H}$ and titration results in normochlorhydric individuals with gastric juice more acid than approximately $p \mathrm{H} 3.0$ (Fig. 1). However, in hypochlorhydria titrations were technically difficult and results bore no constant relation to $p H$ values. In these cases it might be physiologically more correct to titrate the prehistamine juice with $\mathrm{HCl}$ until the posthistamine $p \mathrm{H}$ is reached.

In only two patients with classical adult pernicious anaemia did the augmented histamine test reveal a maximal $p H$ change towards the acid side after histamine stimulation; in neither instance did the $p \mathrm{H}$ fall by more than 1.0 unit. In $93 \%$ of cases the material aspirated became more alkaline. Few papers have been published relating experience with the augmented histamine test in pernicious anaemia, but Helmer, Fouts, and Zerfas (1932) and Kirsner, Nutter, and Palmer (1940) measured acidity changes after smaller doses of histamine and found no significant fall. Shay, Komarov, and Berk (1950) agreed that pernicious anaemia, as a rule, was not associated with increased gastric acidity after histamine, but reported one instance when the $p H$ did fall from $8 \cdot 71$ to $6 \cdot 42$. Recently Jacobs (1958) reported a pronounced fall in $p \mathrm{H}$ in many of his cases of pernicious anaemia, even after fractional test meals with gruel and $0.5 \mathrm{mg}$. of histamine. His results are contrary to our findings and general experience. Abundant acid secretion is frequently found in the rare juvenile pernicious anaemia (Benjamin, 1948; Mollin, Baker, and Doniach, 1955; Stevenson, Little, and Langley, 1956; Harris-Jones, Swan, and Tudhope, 1957), but this condition is not identical with classical adult pernicious anaemia.

True achlorhydria with the augmented histamine test is not pathognomonic of pernicious anaemia. In our 31 patients with true achlorhydria but without pernicious anaemia the diagnoses included hypochromic anaemia, rheumatoid arthritis, steatorrhoea, aplastic anaemia, gastric carcinoma, and the healthy relatives of patients with pernicious anaemia. In such cases the uropepsinogen and absorption of vitamin $B_{12}$ are frequently reduced and in a substantial fraction they are in the range for pernicious anaemia (Fig. 3). The serum vitamin $\mathbf{B}_{12}$ may also be reduced to the levels seen in pernicious anaemia.

The existence of cases in which the absorption of vitamin $B_{12}$ and the levels of vitamin $B_{12}$ in the serum are indistinguishable from those of pernicious anaemia, and yet the patient shows none of the symptoms of pernicious anaemia, no anaemia, glossitis, or subacute combined degeneration, has already been discussed in papers from this Department (Callender and Denborough, 1957; Witts, 1959, 1960). We regard them as examples of 
latent pernicious anaemia. We know that they may remain latent for some years but we do not know the stimulus which causes the anaemia or other symptoms to become manifest. One of the chief applications of the augmented histamine test is in the recognition and study of cases of this kind.

There is no abrupt transition between achlorhydria and normochlorhydria, the gap being bridged by cases of hypochlorhydria in which, in our definition, the gastric juice never becomes more acid than $p \mathrm{H} 3.5$ but there is a fall of more than one $p \mathrm{H}$ unit after maximal stimulation with histamine. Defective absorption of vitamin $B_{12}$, indicative of lack of intrinsic factor, was found only when maximal histamine stimulation failed to produce a significant fall in $p \mathrm{H}$. Previous workers have noticed defective vitamin $B_{12}$ absorption in achlorhydria unassociated with pernicious anaemia, without differentiating between hypochlorhydria and true achlorhydria (MacLean, 1955; Schilling, Clatanoff, and Korst, 1955; Badenoch et al., 1957).

Advanced gastric atrophy microscopically indistinguishable from that found in pernicious anaemia is known to occur in other conditions (Funder and Weiden, 1952; Joske, Finckh, and Wood, 1955; Coghill and Williams, 1958). On the other hand, Magnus (1958) found that only $40 \%$ of his patients with pernicious anaemia had true gastric atrophy; the rest showed extensive atrophic gastritis while $9 \%$ revealed fragments of surviving peptic and parietal cells. These observations imply that there is no pathognomonic anatomical lesion in pernicious anaemia. In the present series of patients not suffering from pernicious anaemia there was no constant relation between severity of atrophy and acid secretion, uropepsinogen, or serum vitamin $B_{12}$ levels, but intrinsic factor became defective only when glandular atrophy was advanced. There was no irrefragable evidence that histological gastric atrophy represents the end-stage of atrophic gastritis. It appears, however, that pernicious anaemia is associated with more complete secretory failure than other conditions where gastric biopsy may reveal atrophy of comparable severity. This might be explained on the basis of a diffuse total atrophy in pernicious anaemia as opposed to a patchy lesion in the other gastritides. It certainly stresses the point that the true state of the gastric mucosa is better assessed by functional investigation than single suction biopsies (Poliner and Spiro, 1958).

It has been suggested that progressive gastric atrophy results in the loss of acid, pepsin, and intrinsic factor in that order (Witts, 1932; Poliner and Spiro, 1958). The present study supports the view that intrinsic factor is lost at a later stage than $\mathrm{HCl}$. Less than half of the achlorhydric patients showed evidence of absent intrinsic factor, while all of those with abnormal absorption of vitamin $B_{12}$ were truly achlorhydric, and had uropepsinogen values in the pernicious anaemia range. Nevertheless, this apparent sequence may be the result of a bias in our method of sampling. We began with patients with apparent achlorhydria. If sampling is done by first testing for intrinsic factor, then a fair proportion of cases will be found in which intrinsic factor is reduced before $\mathrm{HCl}$ is lost (McIntyre, Hahn, Conley, and Glass, 1959). Uropepsinogen bore much the same relation to vitamin $B_{12}$ absorption as did acid secretion, but as uropepsinogen bears no constant relation to gastric pepsin (Hirschowitz, 1957) these findings give no indication as to when pepsin secretion fails.

INDICATIONS FOR USE OF THE AUgmeNTED HistaMINE TEST.-According to present knowledge the augmented histamine test is the most efficient way of stimulating and assessing gastric acid secretion. In clinical research it should be used whenever attempts are made to find a correlation between disease states and the secretory capacity of the stomach.

In routine practice the test is probably of value in two groups of conditions only. In the differential diagnosis of megaloblastic anaemias it is often essential to differentiate achlorhydria from hypochlorhydria. Although conditions such as idiopathic steatorrhoea, megaloblastic anaemia of pregnancy, anaemia due to Diphyllobothrium latum, and megaloblastic anaemia associated with intestinal diverticulosis and blind loops may be associated with achlorhydria, any evidence of acid secretion is strong evidence against pernicious anaemia.

The other indication is in the study of hypersecretory states. Recent work has suggested that total acid output, in milliequivalents per hour, is a valuable figure in deciding the extent of operations for peptic ulcer (Bruce, Card, Marks, and Sircus, 1959). In duodenal ulcer the acid output usually exceeds $35 \mathrm{mEq}$. in the first hour after maximal histamine stimulation, while in gastric ulcer the acid output is significantly lower. The figure for normal adults varies between 10 and $35 \mathrm{mEq}$. per first hour. Stomal ulceration after operations for peptic ulcer is almost invariably associated with persistently high acid secretion.

\section{SUMMARY}

The augmented histamine test was used to investigate the gastric secretion in 30 patients with pernicious anaemia and 136 other subjects suspected of having achlorhydria.

In pernicious anaemia the fasting juice is usually 
more alkaline than $p \mathrm{H} 7 \cdot 0$. There is no increase in the volume of secretion after maximal stimulation with histamine and the juice usually becomes more alkaline. Rarely, the $p \mathrm{H}$ remains unchanged or there is a fractional shift towards the acid side, but always less than 1.0 unit.

We have diagnosed achlorhydria when the gastric juice is at no time more acid than $p \mathrm{H} 3.5$ and when the fall in $p \mathrm{H}$ after maximal stimulation with histamine does not exceed 1.0 unit. If the $p H$ is at no time below 3.5 but the fall after histamine exceeds 1.0 unit, we have diagnosed hypochlorhydria.

In approximately one half of the subjects found to have achlorhydria by less searching methods no specimen more acid than $p \mathrm{H} 3.5$ was obtained after maximal stimulation with histamine. Of these, about two-thirds had complete achlorhydria and one-third hypochlorhydria.

In patients with impaired gastric secretion, not suffering from pernicious anaemia, there was some correlation between gastric acidity, uropepsinogen excretion and serum levels of vitamin $B_{12}$, the lowest mean values being obtained in those with complete achlorhydria.

Reduction of absorption of vitamin $B_{12}$ to the levels characteristic of pernicious anaemia was found only in patients with complete achlorhydria. In such cases the level of vitamin $B_{12}$ in the plasma may also be subnormal. We regard these patients as having latent pernicious anaemia.

The degree of gastric atrophy as determined by biopsy could not be correlated with change of $p \mathrm{H}$ after histamine, excretion of uropepsinogen, or serum levels of vitamin $B_{12}$, but defective absorption of labelled vitamin $B_{12}$ was found only in association with advanced gastric atrophy.

Our thanks are due to Dr. G. H. Spray for serum vitamin $\mathbf{B}_{12}$ assays; Dr. W. C. D. Richards for interpreting the histology; Misses R. Crawley, M. Lorne, B. Mallett, and S. Walton for technical assistance; the Department of Clinical Biochemistry for access to records; and the $X$-ray Department for screening tubes for gastric analysis. This work was in part aided by a grant to Professor L. J. Witts from the Medical Research Council.

\section{REFERENCES}

Aitken, M. A., Spray, G. H., and Walters, G. (1954). Gastric pepsin and the excretion of uropepsinogen in anaemia. Clin. Sci. 13, 119-126.

Anson, M. L. (1938). The estimation of pepsin, trypsin, papain, and catbepsin with hemoglobin. J. gen. Physiol., 22, 79-89.

Badenoch, J., Callender, S. T., Evans, J. R., Spray, G. H., Richards, W.'C. D., Turnbull, A., Wakisaka, G., and Witts, L. J. (1955) Gastric biopsy and radioactive vitamin $B_{3}$ in the study of the Gastric biopsy and radioactive vitamin $\mathrm{B}_{12}$ in the

-, Evans, J. R., and Richards, W. C. D. (1957). The stomach in hypochromic anaemia. Brit. J. Haemat., 3, 175-185.

Benjamin, B. (1948). Infantile form of pernicious (Addisonian) anemia. Amer. J. Dis. Child., 75, 143-189.
Bruce, J., Card, W. I., Marks, I. N., and Sircus, W. (1959). The rationale of selective surgery in the treatment of duodenal ulcer. J. roy. Coll. Surg. Edinb., 4, 85-104.

Callender, S. T., and Denborough, M. A. (1957). A family study of pernicious anaemia. Brit. J. Haemat., 3, 88-106.

Card, W. I., Marks, I. N., and Sircus, W. (1955). Observations on achlorhydria. J. Physicl. (Lond.), 130, 18P.

$\longrightarrow$, and Sircus, W. (1958). Anacidity. In Modern Trends in Gastro-enterology (second series, ed. F. Avery Jones, pp. 177192. Butterworths, London.

Coghill, N. F., and Williams, A. Wynn (1958). The gastric mucosa in hypochromic anaemia. Proc. roy. Soc. Med., 51, 464.

Denborough, M. A., Retief, F. P., and Witts, L. J. (1958), Tubeless gastric analysis. Brit. med.J., 1, 1213-1215.

Funder, J. F., and Weiden, S. (1952). The correlation between test meal findings and the histology of the stomach as shown by gastric biopsy. Med. J. Aust., 1, 600-602.

Harris-Jones, J. N., Swan, H. T., and Tudhope, G. R. (1957). Pernicious anemia without gastric atrophy and in the presence of free hydrochloric acid. Blood, 12, 461-468.

Helmer, O. M., Fouts, P. J., and Zerfas, L. G. (1932). Gastrointestinal studies: I. Gastric juice in pernicious anemia. J. clin. Invest. 11, 1129-1153.

Hirschowitz, B. I. (1957). Pepsinogen: its origins, secretion and excretion. Physiol. Rev., 37, 475-511.

Jacobs, A. (1958). Acid secretion by the stomach in pernicious anaemia. Brit. J. Haemat. 4, 465-469.

Joske, R. A., Finckh, E. S., and Wood, I. J. (1955). Gastric biopsy: a study of 1,000 consecutive successful gastric biopsies. Quart. J. Med., 48, (n.s. 24), 269-294.

Kay, A. W. (1953). Effect of large doses of histamine on gastric secretion of $\mathrm{HCl}$; an augmented histamine test. Brit. med. J., 2, 77-80.

- (1958). Anaemia and the alimentary tract; investigation of gastric secretion, Royal College of Physicians Conference. Lancet, $2,257$.

Kirsner, J. B., Nutter, P. B., and Palmer, W. L. (1940). Studies on anacidity: the hydrogen-ion concentration of the gastric secretion, the gastroscopic appearance of the gastric mucosa, and the presence of a gastric secretory depressant in patients with anacidity. J. clin. Invest., 19, 619-625.

McIntyre, P. A., Hahn, R., Conley, C. L., and Glass, B. (1959). Genetic factors in predisposition to pernicious anemia. Bull. Johns Hopk. Hosp., 104, 309-342.

MacLean, L. D. (1955)." The differentiation of achylia gastrica and achlorhydria by means of radioactive vitamin $\mathbf{B}_{12}$. Gastroenterology, 29, 653-665.

Magnus, H. A. (1958). Anaemia and the alimentary tract: the stomach. Royal College of Physicians Conference. Lancet, $2,256$.

Marks, I. N. (1956). The relationship of the acid output to the parietal cell population of the stomach. Scot. med. J., 1, 242 .

Mollin, D. L., Baker, S. J., and Doniach, I. (1955). Addisonian pernicious anaemia without gastric atrophy in a young man. Brit. J. Haemat., 1, 278-290.

Poliner, I. J., and Spiro, H. M. (1958). The independent secretion of acid, pepsin and "intrinsic factor" by the human stomach. Gastroenterology, 34, 196-209.

Polland, W. S. (1933). Histamine test meals. An analysis of 983 consecutive tests. Arch. intern. Med., 51, 903-919.

Retief, F. P. (1959). A study of achlorhydria and its relation to anaemia. D. Phil. Thesis, Oxon.

Schilling, R. F., Clatanoff, D. V., and Korst, D. R. (1955). Intrinsic factor studies: III. Further observations utilizing the urinary radioactivity test in subjects with achlorhydria, pernicious

Shay, anemia or a total gastrectomy. J. lab. clin. Med., 45, 926-934. the clinical measurement of gastric acidity with special reference the clinical measurement of gastric acidity with special

$\longrightarrow,-$ Siplet, H., and Fels, S. S. (1946). A gastric mucigogue action of the alkyl sulfates. Science, 103, 50-52.

Spray, G. H. (1955). An improved method for the rapid estimation of vitamin $B_{13}$ in serum. Clin. Sci., 14, 661-667.

- and Witts, L. J. (1958). Results of three years' experience with microbiological assay of vitamin $\mathrm{B}_{12}$ in serum. Brit. med. J., 1, 295-298.

Stevenson, T. D., Little, J. A., and Langley, L. (1956). Pernicious anemia in childhood. New Engl. J. Med., 255, 1219-1223.

Van Goidsenhoven, G., Wilkoff, L., and Kirsner, J. B. (1958). Serum and urine pepsinogen and gastric pepsin. Simultaneous analyses for 24-hour periods in normal persons and in patients with duodenal ulcer, gastric ulcer and achlorhydria. Gastroenterology, 34, 421-435.

Witts, L. J. (1932). The pathology and treatment of anaemia; the anhaemopoietic anaemias. Lancet, 1, 549-557.

(1959). Achlorhydria and anaemia. Canad. med. Serv. J., 15,645 .

(1960). The development of pernicious anaemia. Proc. 7th Europ. Congr. Haemat. To be published.

Wood, I. J., Doig, R. K., Motteram, R., Weiden, S., and Moore, A. (1949). The relationship between the secretions of the gastric mucosa and its morphology as shown by biopsy specimens. Gastroenterology, 12, 949-958. 